\title{
Noninvasive Respiratory Support of Juvenile Rabbits by High-Amplitude Bubble Continuous Positive Airway Pressure
}

\author{
ROBERT M. DIBLASI, JAY C. ZIGNEGO, DENNIS M. TANG, JACK HILDEBRANDT, CHARLES V. SMITH, \\ THOMAS N. HANSEN, AND C. PETER RICHARDSON
}

Center for Developmental Therapeutics [R.M.D., J.C.Z., D.M.T., C.V.S., T.N.H., C.P.R.], Seattle Children's Research Institute, Seattle, WA 98101; Department of Physiology and Biophysics [J.H.], University of Washington School of Medicine, Seattle, WA 98195

\begin{abstract}
Bubble continuous positive airway pressure (BCPAP) applies small-amplitude, high-frequency oscillations in airway pressure $\left(\Delta \mathrm{P}_{\mathrm{aw}}\right)$ that may improve gas exchange in infants with respiratory disease. We developed a device, high-amplitude B-CPAP (HAB-CPAP), which provides greater $\Delta \mathrm{P}_{\text {aw }}$ than $\mathrm{B}-\mathrm{CPAP}$ provides. We studied the effects of different operational parameters on $\Delta \mathrm{P}_{\mathrm{aw}}$ and volumes of gas delivered to a mechanical infant lung model. In vivo studies tested the hypothesis that HAB-CPAP provides noninvasive respiratory support greater than that provided by B-CPAP. Lavaged juvenile rabbits were stabilized on ventilator nasal CPAP. The animals were then supported at the same mean airway pressure, bias flow, and fraction of inspired oxygen $\left(\mathrm{F}_{\mathrm{i}} \mathrm{O}_{2}\right)$ required for stabilization, whereas the bubbler angle was varied in a randomized crossover design at exit angles, relative to vertical, of 0 (HABCPAP0; equivalent to conventional B-CPAP), 90 (HAB-CPAP90), and $135^{\circ}$ (HAB-CPAP135). Arterial blood gases and pressure-rate product (PRP) were measured after $15 \mathrm{~min}$ at each bubbler angle. $\mathrm{PaO}_{2}$ levels were higher $(p<0.007)$ with HAB-CPAP135 than with conventional B-CPAP. $\mathrm{PaCO}_{2}$ levels did not differ $(p=0.073)$ among the three bubbler configurations. PRP with HAB-CPAP135 were half of the PRP with HAB-CPAP0 or HAB-CPAP90 ( $p=$ $0.001)$. These results indicate that HAB-CPAP135 provides greater respiratory support than conventional B-CPAP does. (Pediatr Res 67: 624-629, 2010)
\end{abstract}

$\mathrm{B}$ ubble-nasal continuous positive airway pressure (BnCPAP) is a form of noninvasive respiratory support that is used frequently as a primary strategy for supporting spontaneously breathing preterm infants at risk of developing respiratory distress syndrome. Compared with intubation and mechanical ventilation, the use of B-CPAP has been associated with lower indicators of acute lung injury (1) and bronchopulmonary dysplasia (2).

Recent studies suggest that the bubbling of gas exiting the B-nCPAP circuit at the water seal creates oscillations in airway pressure $\left(\Delta \mathrm{P}_{\mathrm{aw}}\right)$, having broadband high frequencies

Received September 28, 2009; accepted March 1, 2010.

Correspondence: Robert M. DiBlasi, RRT-NPS, Seattle Children's Research Institute M/S, C9S-9, 1900 Ninth Avenue, Seattle, WA 98101; e-mail: robert.diblasi@ seattlechildrens.org This research was funded by the Seattle Children's Research Institute.

Seattle Children's Research Institute (SCRI) has submitted a patent application to the World Intellectual Property Organization (PCT/US2009/039957) concerning the HABCPAP device described in this article. The application is in review and has not yet been approved. However, authors R.M.D., J.C.Z., C.V.S., T.N.H., and C.P.R., who are listed as inventors on the application, could benefit from the invention.

Supplemental digital content is available for this article. Direct URL citations appear in the printed text and are provided in the HTML and PDF versions of this article on the journal's Web site (www.pedresearch.org).
(3), which may promote airway patency and enhance lung volume and gas exchange in preterm lambs (4). However, a study of 261 consecutively born premature infants revealed that $24 \%$ of infants born weighing $<1250 \mathrm{~g}$ and $50 \%$ of infants weighing $<750 \mathrm{~g}$ failed B-nCPAP and required endotracheal intubation and mechanical ventilation (5). In an effort to diminish the potentially deleterious effects of invasive mechanical ventilation (6), we designed a novel device, highamplitude B-CPAP (HAB-CPAP), which, through alterations in angle of gas entry at the water seal, may enhance respiratory efficiency and improve oxygenation when compared with conventional B-nCPAP.

In this report, we describe a device that provides $\Delta \mathrm{P}_{\mathrm{aw}}$ higher in amplitude than B-CPAP. Studies were conducted to determine the effects of bubbler angle and bias flow on $\Delta \mathrm{P}_{\mathrm{aw}}$ and the amplitude of oscillations in volume $(\Delta \mathrm{V})$ delivered to a mechanical model of an infant lung. In addition, studies were conducted in spontaneously breathing, lung lavaged, adolescent rabbits to test the hypothesis that HAB-CPAP would provide greater gas exchange and lower inspiratory work of breathing (WOB), as estimated by pressure-rate product (PRP, an index of WOB), than are provided by conventional B-nCPAP.

\section{MATERIALS AND METHODS}

HAB-CPAP device. The HAB-CPAP device consisted of a dual limb patient/subject circuit. The inhalation limb provided bias flow gas from a flowmeter through a 4.8-mm ID Tygon tubing to the test lung or animal, and the exhalation limb conveyed exhaled and bias flow gases through a 8-mm ID Tygon tubing connected distally to an elbow, a swivel, and a bubbler (online supplement: http://links.lww.com/PDR/A58). The swivel allowed for adjustments in bubbler angle from 0 to $180^{\circ}$. A bubbler angle of $0^{\circ}$ represented the tube pointing straight down and is equivalent to conventional B-CPAP. The abbreviations HAB-CPAP0, HAB-CPAP90, and HAB-CPAP135 designate the $\mathrm{HAB}-\mathrm{CPAP}$ device at bubbler angles of 0,90 , and $135^{\circ}$, respectively, although low angles do not provide high-amplitude $\Delta \mathrm{P}_{\mathrm{aw}}$. CPAP levels were adjusted by the depth of immersion of the bubbler in the water column, and they were defined as mean airway pressure (MAP) monitored proximal to the patient/subject interface.

\footnotetext{
Abbreviations: $\Delta \mathbf{P}_{\mathbf{a w}}$, oscillations in airway pressure; $\mathbf{\Delta V}$, oscillations in volume; ABG, arterial blood gas analysis(es); B-CPAP, bubble CPAP; CPAP, continuous positive airway pressure; $\mathbf{F i O}_{2}$, fraction of inspired oxygen; HAB-CPAP, high-amplitude B-CPAP; HFOV, high-frequency oscillatory ventilation; MAP, mean airway pressure; $\mathbf{P}_{\mathbf{a w}}$, airway pressure; $\mathbf{P}_{\mathbf{e s}}$, esophageal pressure; PRP, pressure rate product(s); $\mathbf{S p O}_{2}$, pulse oximeter oxygen saturation(s); WOB, work of breathing
} 


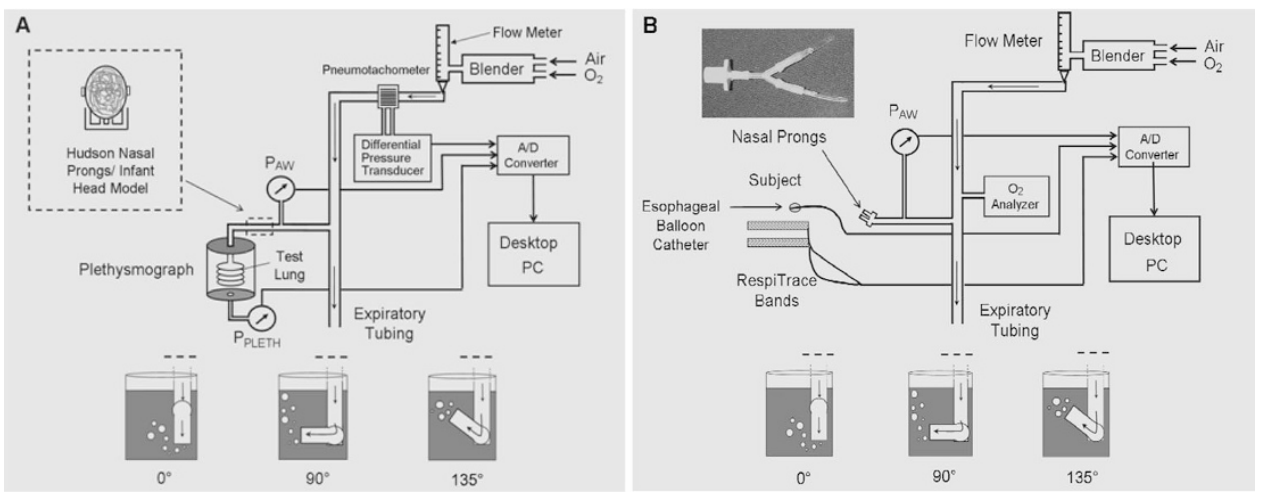

Figure 1. HAB-CPAP device and study systems. The system in $1 A$ was used for testing in vitro and in $1 B$ was used for supporting rabbits in vivo through nasal prongs. The configuration with the bubbler straight down (labeled $0^{\circ}$ ) is equivalent to conventional bubble CPAP. The bubblers were also configured at angles of 90 and $135^{\circ}$, as indicated; $\mathrm{PC}$, personal computer; A/D converter, analog to digital converter.

Infant test lung model. We designed an infant airway model consisting of an infant mannequin head affixed with "leaky" nasal prongs (Fig. 1A insert) to evaluate the effects of pressure oscillations on gas volume delivered to a test lung during HAB-CPAP (Fig. 1A). The infant airway model was connected in series to an infant test lung placed inside a plethysmograph. The test lung compliance and resistance were $0.53 \mathrm{~mL} / \mathrm{cm} \mathrm{H}_{2} \mathrm{O}$ and $185 \mathrm{~cm} \mathrm{H}_{2} \mathrm{O} / \mathrm{L} / \mathrm{s}$, respectively. The methods and descriptions used to determine mechanics, leak magnitude of the prongs, and calibration of the plethysmograph are described in an online supplement (http://links.lww.com/PDR/A58). Outputs from the airway pressure $\left(\mathrm{P}_{\mathrm{aw}}\right)$, plethysmograph pressure, and differential pressure (bias flow) transducers were recorded on a personal computer. The percentages of bias flows leaking around the nasal prongs at a MAP of $7 \mathrm{~cm} \mathrm{H}_{2} \mathrm{O}$ and bias flows of $4,6,8$, and $10 \mathrm{~L} / \mathrm{min}$ were $80.6,53.7,40.3$, and $32.2 \%$, respectively.

The amplitudes of $\Delta \mathrm{P}_{\mathrm{aw}}$ and $\Delta \mathrm{V}$ delivered to the lung model were measured while the HAB-CPAP circuit was connected directly to the lung model without a nasal interface, at a bias flow of $6 \mathrm{~L} / \mathrm{min}$, and with bubbler angles ranging from 0 to $180^{\circ}$. In addition, amplitudes of oscillations were measured with the HAB-CPAP circuit attached to the infant airway model via nasal prongs, and bubbler was depth adjusted to control MAP at $7.0 \pm 0.1 \mathrm{~cm}$ $\mathrm{H}_{2} \mathrm{O}$, with bias flows of 2 to $12 \mathrm{~L} / \mathrm{min}$ and bubbler angles of 0,90 , and $135^{\circ}$.

With HAB-CPAP135, bubble motion was recorded at 800 frames/s (Phantom Version9.1; Vision Research, Wayne, NJ) in parallel with a signal acquisition module (SAM3; Vision Research) to record $\mathrm{P}_{\mathrm{aw}}$ at $12 \mathrm{kHz}$ and visualized using CineViewer software (Version 9.1.663.0; Vision Research) on a desktop personal computer. For visual clarity, clear plastic pieces were used to collect these data instead of the more opaque pieces used in the other studies, but the component dimensions of the bubblers were the same, and pressure wave forms were similar.

Animal model. Under an protocol approved by the Seattle Children's Research Institute's Institutional Animal Care and Use Committee (IACUC), 12 juvenile female New Zealand white rabbits weighing $1.58 \pm 0.02 \mathrm{~kg}$ were anesthetized with $33 \mathrm{mg} / \mathrm{kg}$ ketamine, $6.6 \mathrm{mg} / \mathrm{kg}$ xylazine, and $1 \mathrm{mg} / \mathrm{kg}$ acepromazine, intramuscularly. After instrumentation, anesthesia was administered continuously as per protocol (online supplement: http://links.lww.com/PDR/A58). Animals were intubated orally and ventilated on assist/control mode (Hamilton Medical, Reno, NV) at 30 breaths/min, 0.4 fraction of inspired oxygen $\left(\mathrm{FiO}_{2}\right), 0.35$-s inspiratory time, $4 \mathrm{~cm} \mathrm{H}_{2} \mathrm{O}$ positive end-expiratory pressure (PEEP), and tidal volumes targeted to $7 \mathrm{~mL} / \mathrm{kg}$. The endotracheal tube was tied in place with umbilical tape to prevent displacement and leakage of gas and saline during lavage. Pulse oximeter oxygen saturations $\left(\mathrm{SpO}_{2}\right)$ were measured (Massimo, Irvine, $\mathrm{CA}$ ) on the animal's lower leg. The ventilator respiratory rates (RRs) were adjusted to maintain $\mathrm{PaCO}_{2}$ between 35 and $45 \mathrm{~mm} \mathrm{Hg}$.

The $\mathrm{FiO}_{2}$ was increased to 1.0 , and the lungs were lavaged four times with $30 \mathrm{~mL} / \mathrm{kg}$ of normal $(0.9 \%)$ saline warmed to body temperature, with 5 -min recoveries between lavages. Whenever $\mathrm{SpO}_{2}$ values were $>92 \%$, additional lavages were administered. Animals required nomore than six lavages. Ventilation was adjusted to maintain volume target at $5 \mathrm{~mL} / \mathrm{kg}$, and PEEP was set at $6 \mathrm{~cm} \mathrm{H} \mathrm{H}_{2} \mathrm{O}$. The RRs were set initially at 60 breaths/min and adjusted upward to a maximum of 120 breaths/min to maintain $\mathrm{PaCO}_{2}$ between 45 to $55 \mathrm{~mm} \mathrm{Hg}$. Animals were stabilized on mechanical ventilation for $0.5 \mathrm{~h}$.

Double-lumen esophageal balloon catheters/orogastric tubes were positioned (Cardinal Healthcare, Dublin, $\mathrm{OH}$ ) in the lower esophagus and inflated with $0.4 \mathrm{~mL}$ of air. Placement of the catheters was confirmed using the occlusion technique (7). Esophageal pressure changes $\left(\Delta \mathrm{P}_{\mathrm{es}}\right)$ were used to approximate changes in pleural pressures and used in the calculations of PRPs. The PRP is the product of $\Delta \mathrm{P}_{\mathrm{es}}$ and $\mathrm{RR}$ and is used as an index of inspiratory WOB (8). Abdominal and thoracic Respitrace (Cardinal Health- care, Dublin, $\mathrm{OH}$ ) bands were used to confirm the initiation of breaths used in PRP calculations. The orogastric tube was connected to low intermittent suction to prevent gastric distention.

The spontaneously breathing animals were weaned to ventilator CPAP of $6 \mathrm{~cm} \mathrm{H}_{2} \mathrm{O}$ and extubated. Custom nasal prongs constructed using silicone tubing to connect two $4 \mathrm{~cm}$-lengths of $3.0 \mathrm{~mm}$ ID endotracheal tubes to a plastic "Y" and to an endotracheal tube adapter (3.0 mm ID-15 mm OD) (Fig. $1 B$ insert) were fitted and attached to the ventilator. Airway patency through the nasal prongs was confirmed using end-tidal carbon dioxide monitoring (Microstream; Oridion, Needham, MA). $\mathrm{FiO}_{2}$, measured with an in-line $\mathrm{O}_{2}$ analyzer $\left(\mathrm{MaxO}_{2}\right.$ plus; Cardinal Health, Dublin, $\left.\mathrm{OH}\right)$, and CPAP were adjusted to provide $\mathrm{SpO}_{2}$ between 85 and $92 \%$. A customized chin strap, as commonly applied in infants receiving nCPAP (9), was adapted to prevent large volumes of gas from leaking through the mouth.

After a stabilization period of $30 \mathrm{~min}$ on ventilator nCPAP, arterial blood gas analyses (ABG), MAP, and arterial blood pressures were measured. Each animal was then randomized using a crossover sequence to the HAB-CPAP at bubbler configurations of 0,90 , and $135^{\circ}$ (Fig. 2A), with the same MAP, system bias flow, and $\mathrm{FiO}_{2}$ established during ventilator nCPAP. ABG, $\mathrm{P}_{\mathrm{aw}}$, $\mathrm{P}_{\mathrm{es}}$, Respitrace, and arterial blood pressure were recorded at the end of each 15-min period of support.

Analyses. An algorithm was developed to estimate $\Delta \mathrm{P}_{\text {aw }}$ and $\Delta \mathrm{V}$ delivered to the infant lung model and to determine the frequency of oscillations with the greatest magnitude (dominant frequencies), and bandwidth of oscillations. Methods for estimating amplitude and frequency of $\Delta \mathrm{P}_{\text {aw }}$ and $\Delta \mathrm{V}$ are detailed in the online Supplement (http://links.lww.com/PDR/A58).

Statistics. Data are expressed as mean \pm SEM. Data from the bench studies were assessed by one- or two-way ANOVA, with Newman-Keuls tests post hoc. Data from studies in rabbits were assessed by pairwise comparisons for repeated-measures ANOVA model, adjusted for period, with Bonferroni's adjustments for the multiple comparisons. Statistical differences are indicated at $p<0.05$.

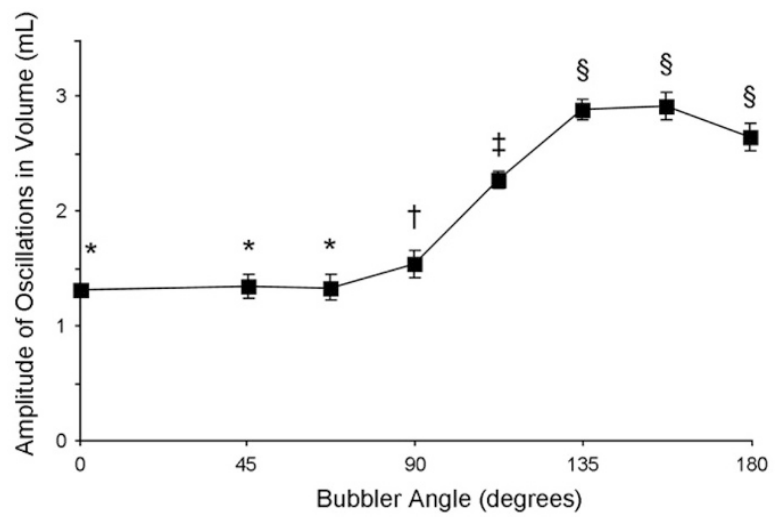

Figure 2. Effect of bubbler angle on volumes delivered to test lung by HAB-CPAP. Data are mean \pm SEM for $8 \mathrm{~s}$ of recorded data with bias flow of $6 \mathrm{~L} / \mathrm{min}$ and no nasal interface or leak. Data were analyzed with one-way ANOVA, with Newman-Keuls post hoc. Data not sharing common symbols are different from each other, $p<0.05$. 


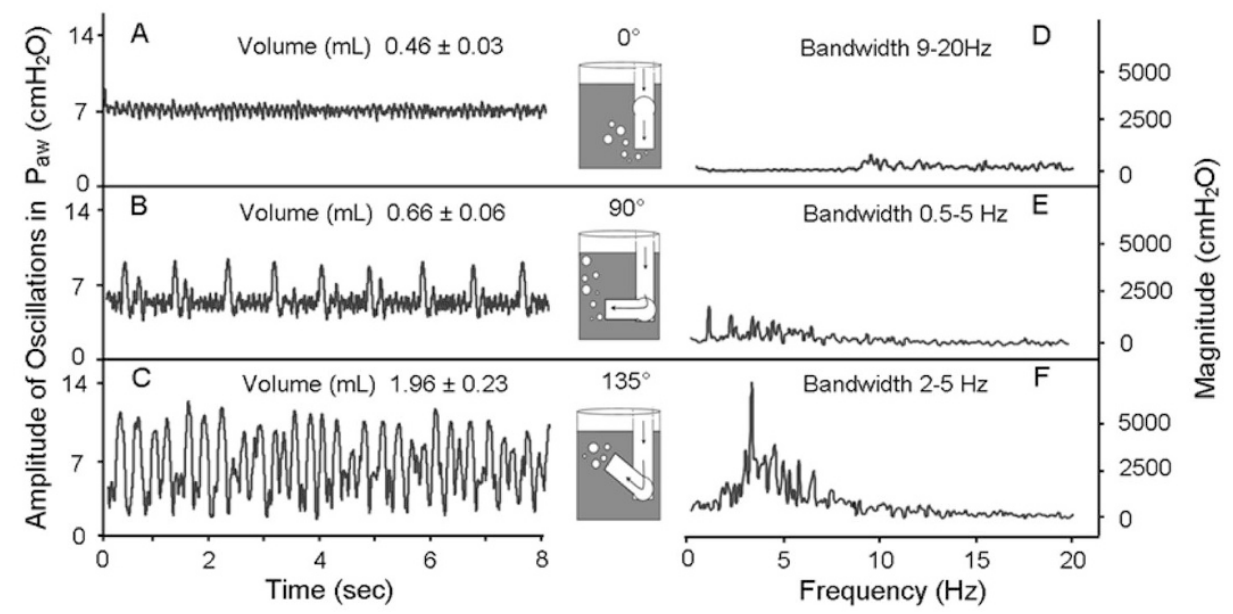

Figure 3. Airway pressure $(A, B$, and $C)$ and power spectral analyses of airway pressure $(D, E$, and $F)$ while connected to the silastic test lung at a bias flow setting of $8 \mathrm{~L} / \mathrm{min}$ recorded over $8 \mathrm{~s}$.

\section{RESULTS}

Bench studies. Adjusting bubbler angle greatly affected $\Delta \mathrm{P}_{\mathrm{aw}}$ and $\Delta \mathrm{V}$ delivered to the test lung. The $\Delta \mathrm{V}$ did not change when the bubbler angle was increased from 0 through $67^{\circ}$, increased markedly from 67 through $135^{\circ}$, and plateaued at angles from 135 to $180^{\circ}$ (Fig. 2). Ventilating through nasal prongs attached to the infant airway model also resulted in increases in $\Delta \mathrm{P}_{\mathrm{aw}}$ and $\Delta \mathrm{V}$ as bubbler angles were increased from 0 to $90^{\circ}$ and $135^{\circ}$ (Fig. $3 A-C$ ). With HAB-CPAP0, $\Delta \mathrm{P}_{\text {aw }}$ was $1.2 \pm .1 \mathrm{~cm} \mathrm{H}_{2} \mathrm{O}$ (Fig. $3 A$ ) with a dominant frequency of $10.2 \mathrm{~Hz}$ (Fig. $3 D$ ). With HAB-CPAP90, $\Delta \mathrm{P}_{\mathrm{aw}}$ was $3.6 \pm 0.0$ cm $\mathrm{H}_{2} \mathrm{O}$ (Fig. $3 B$ ) with a dominant frequency of $1.4 \mathrm{~Hz}$ (Fig. $3 E$ ). However, additional superimposed oscillations of $1.7 \pm$ $0.0 \mathrm{~cm} \mathrm{H}_{2} \mathrm{O}$ at a dominant frequency near $10.8 \mathrm{~Hz}$ were noted, resulting in an overall average $\Delta \mathrm{P}_{\text {aw }}$ of $1.8 \pm 0.1 \mathrm{~cm} \mathrm{H}_{2} \mathrm{O}$. With HAB-CPAP135, $\Delta \mathrm{P}_{\text {aw }}$ was $4.5 \pm 0.5 \mathrm{~cm} \mathrm{H}_{2} \mathrm{O}$ (Fig. $3 C$ ), with a dominant frequency of $3.1 \mathrm{~Hz}$ (Fig. $3 F$ ). The depths of the tip of the bubbler, where gas exited the bubbler into the water,
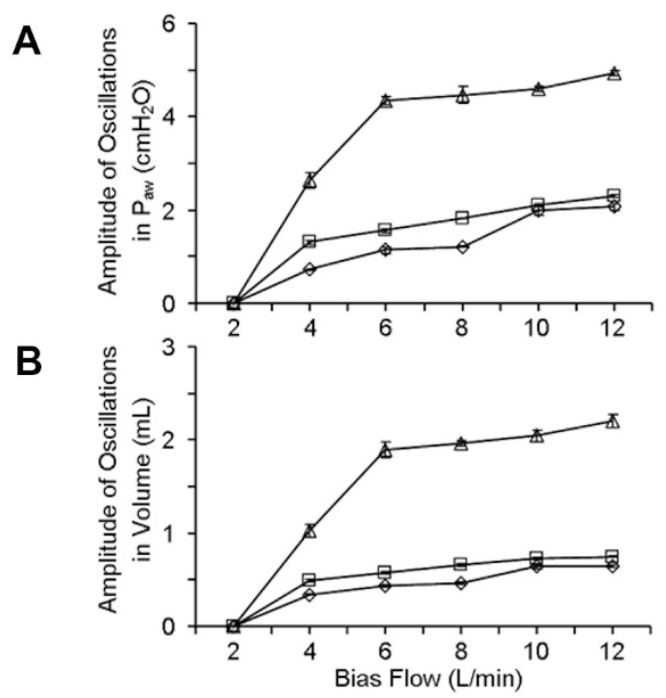

Figure 4. Effects of bias flow on $\mathrm{P}_{\mathrm{aw}}$ and volumes delivered to the infant head model and test lung at the three bubbler angles shown. Measurements were made at the respective bias flow settings at bubbler angles of $0(\diamond), 90$ $(\square)$, and $135^{\circ}(\Delta)$. Each data point is the mean \pm SEM, for three separate 8-s runs. below the water surface were $6.9,5.3$, and $2.4 \mathrm{~cm}$ at $\mathrm{HAB}$ CPAP0, HAB-CPAP90, and HAB-CPAP135, respectively.

The effects of bias flow on $\Delta \mathrm{P}_{\mathrm{aw}}$ and $\Delta \mathrm{V}$ were not as great as the effects of bubbler angle. At a bias flow of $2 \mathrm{~L} / \mathrm{min}$, the MAP was $2.2 \mathrm{~cm} \mathrm{H}_{2} \mathrm{O}$ at all bubbler depths $>2.2 \mathrm{~cm}$ below the water surface. All gas flowed through the leak around the nasal prongs, and none exited through the bubbler. Thus, at bias flows $\leq 2 \mathrm{~L} / \mathrm{min}$, the values for $\Delta \mathrm{P}_{\text {aw }}$ and $\Delta \mathrm{V}$ were 0 at all bubbler configurations (Fig. 4). During HAB-CPAP0 and HAB-CPAP90, increasing the bias flow from 4 to $12 \mathrm{~L} / \mathrm{min}$ had only modest effects on the magnitude of $\Delta \mathrm{P}_{\mathrm{aw}}$ and did not result in appreciable differences in $\Delta \mathrm{V}$. However, with $\mathrm{HAB}$ CPAP135, relatively large increases in $\Delta \mathrm{P}_{\mathrm{aw}}$ and $\Delta \mathrm{V}$ were observed as bias flows were increased from 2 to $6 \mathrm{~L} / \mathrm{min}$, with little changes thereafter (Fig $4 A$ and $B$, respectively). At bias flows from 4 through $12 \mathrm{~L} / \mathrm{min}, \Delta \mathrm{P}_{\mathrm{aw}}$ and $\Delta \mathrm{V}$ were markedly higher with HAB-CPAP135 than with HAB-CPAP90 or HAB-
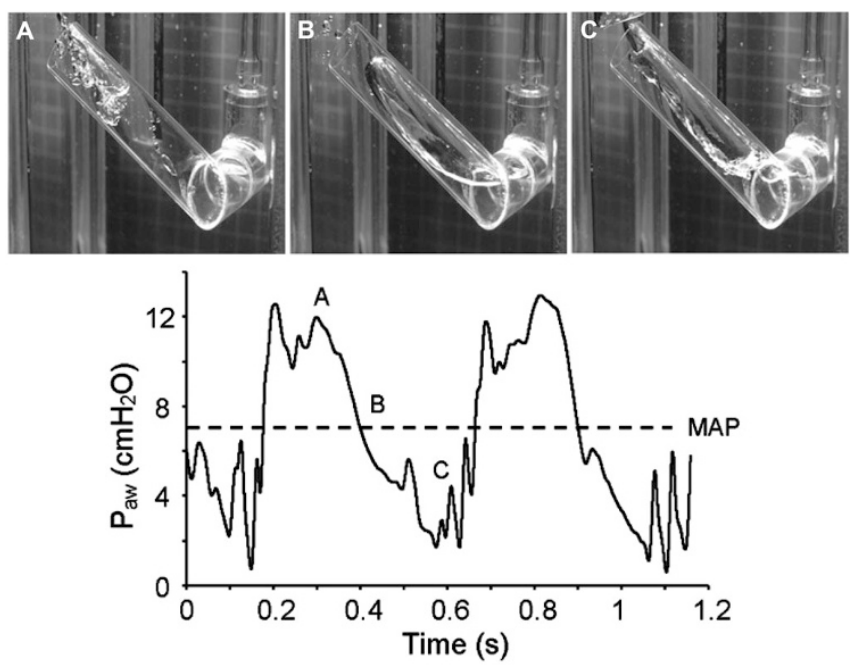

Figure 5. Correlation of $\mathrm{P}_{\mathrm{aw}}$ with frames of high-speed videos showing the successive positions of the gas/water interface in the HAB-CPAP135 bubbler. Point $A$ represents the maximum $\mathrm{P}_{\mathrm{aw}}$ observed at the time when the gas/water interface just enters the horizontal piece. There is a gradual decrease in $\mathrm{P}_{\mathrm{aw}}$ as the contiguous bubble progresses up the $135^{\circ}$ portion of the bubbler (Point B). As the gas exits, water reenters the bubbler resulting in relatively highfrequency oscillations in $\mathrm{P}_{\mathrm{aw}}$ (Point $C$ ). 
CPAP0 (Fig. 4). In most testing conditions, increasing bias flow raised the dominant frequency and bandwidths of $\Delta \mathrm{P}_{\mathrm{aw}}$.

High speed videos showed water oscillating in the bubbler at frequencies consistent with the fast Fourier transform results. Figure 5 displays still frames of a typical oscillation cycle along with a tracing of $\mathrm{P}_{\mathrm{aw}}$. At time $0.17 \mathrm{~s}, \mathrm{P}_{\mathrm{aw}}$ rose rapidly as a bubble formed at the entrance to the horizontal portion of the bubbler and $\mathrm{P}_{\mathrm{aw}}$ plateaued as the bubble progressed along the horizontal portion (Point A). $\mathrm{P}_{\text {aw }}$ began to decrease when the bubble rounded the corner into the $135^{\circ}$ portion of the bubbler at the time $0.35 \mathrm{~s}$ and continued to decline as the bubble rose in the bubbler (Point B), sustaining a column of gas still continuous with the airway. $\mathrm{P}_{\mathrm{aw}}$ was minimal when the contiguous bubble expanded to maximum height, just beyond the tip of the bubbler, at time $0.57 \mathrm{~s}$. As the rising bubble separated from the bubbler, water rushing into the bubbler interrupted the gas flow in a somewhat chaotic fashion (Point $C$ ) concomitant with high-frequency $\Delta \mathrm{P}_{\text {aw }}$ followed by the initiation of another cycle near the time $0.63 \mathrm{~s}$.

Animal studies. Lavaging decreased lung compliances in rabbits from $1.22 \pm 0.06$ to $0.55 \pm 0.03 \mathrm{~mL} / \mathrm{cm} \mathrm{H}_{2} \mathrm{O}(p<$ 0.001). The MAP established for each animal on ventilator CPAP were applied in the subsequent studies with HABCPAP. No differences were observed in heart rate $(p=0.75)$ or arterial blood pressure $(p=0.60)$, when the animals were managed at the different bubbler angle configurations (Table 1).
Before randomization, the animals exhibited a range of respiratory compromise, with oxygenation index (OI) ranging from 1.7 to 10.6 and $\mathrm{FiO}_{2}$ ranging from 0.25 to 0.70 (Table 1); however, all animals were able to be managed appropriately with HAB-CPAP. The $\mathrm{PaO}_{2}$ levels were slightly higher $(p=$ 0.007 ) with HAB-CPAP135 and B-CPAP90 than with HABCPAP0 (Fig. 6A) $\mathrm{PaCO}_{2}$ levels among treatment groups were not different ( $p=0.073$; Fig. $6 B$ ). The PRP values were lower $(p=0.001)$ during HAB-CPAP135 than during the other bubbler configurations (Fig. 6C). During HAB-CPAP135, two of the animals (animals 4 and 9) with normal $\mathrm{PaCO}_{2}$ (41 and $49 \mathrm{~mm} \mathrm{Hg}$, respectively) and vital signs stopped spontaneous respiratory efforts. Even with omission of the PRP data from these apneic animals, PRP for the animals on HAB-CPAP135 were lower than on the other HAB-CPAP configurations (data not shown). RR during HAB-CPAP135 were lower than with HAB-CPAP90 ( $p=0.030)$, but not different $(p=0.068)$ from RR with HAB-CPAP0 (Table 2). The levels of $\Delta \mathrm{P}_{\mathrm{es}}$ were lower during HAB-CPAP135 than during HAB-CPAP0 $(p=$ $0.006)$ or HAB-CPAP90 $(p=0.015)$, and the levels of $\Delta \mathrm{P}_{\mathrm{es}}$ at HAB-CPAP0 and HAB-CPAP90 did not differ (Table 2). The sequence of support of individual animals with HABCPAP0, HAB-CPAP90, or HAB-CPAP135 and the respective OI are listed in the online supplement (Table S1: http://links.lww.com/PDR/A58). No animals developed pneumothoraces or gastric insufflation that might result in

Table 1. Physiologic parameters of lung-lavaged rabbits supported by ventilator nasal CPAP before to randomization to HAB-CPAP

\begin{tabular}{|c|c|c|c|c|c|c|c|c|c|c|c|}
\hline Animal & $\begin{array}{l}\text { Weight } \\
(\mathrm{kg})\end{array}$ & $\begin{array}{l}\text { Lavages } \\
\quad(n)\end{array}$ & $\mathrm{FiO}_{2}$ & $\begin{array}{c}\text { MAP } \\
\left(\mathrm{cm} \mathrm{H}_{2} \mathrm{O}\right)\end{array}$ & $\begin{array}{c}\mathrm{PaO}_{2} \\
(\mathrm{~mm} \mathrm{Hg})\end{array}$ & $\begin{array}{c}\mathrm{PaCO}_{2} \\
(\mathrm{~mm} \mathrm{Hg})\end{array}$ & $\mathrm{pH}$ & OI & $\underset{\left(\min ^{-1}\right)}{\mathrm{HR}}$ & $\begin{array}{c}\mathrm{BP} \\
(\mathrm{mm} \mathrm{Hg})\end{array}$ & $\begin{array}{c}\mathrm{RR} \\
\left(\mathrm{min}^{-1}\right)\end{array}$ \\
\hline 1 & 1.68 & 4 & 0.70 & 10.4 & 69 & 72 & 7.20 & 10.6 & 218 & 51 & 90 \\
\hline 2 & 1.45 & 4 & 0.40 & 7.8 & 55 & 79 & 7.15 & 7.7 & 234 & 43 & 129 \\
\hline 3 & 1.68 & 4 & 0.30 & 7.0 & 64 & 65 & 7.23 & 3.3 & 238 & 48 & 52 \\
\hline 4 & 1.58 & 5 & 0.30 & 5.8 & 81 & 61 & 7.28 & 2.1 & 215 & 52 & 105 \\
\hline 5 & 1.60 & 5 & 0.55 & 9.4 & 74 & 96 & 7.09 & 7.0 & 223 & 62 & 114 \\
\hline 6 & 1.60 & 4 & 0.31 & 5.8 & 67 & 56 & 7.30 & 2.7 & 227 & 59 & 108 \\
\hline 7 & 1.54 & 5 & 0.31 & 5.3 & 89 & 62 & 7.26 & 1.7 & 195 & 65 & 96 \\
\hline 8 & 1.62 & 4 & 0.31 & 7.2 & 58 & 71 & 7.21 & 3.8 & 221 & 50 & 114 \\
\hline 9 & 1.58 & 4 & 0.25 & 4.9 & 51 & 45 & 7.32 & 2.4 & 219 & 46 & 86 \\
\hline 10 & 1.58 & 5 & 0.43 & 5.9 & 75 & 93 & 7.09 & 3.4 & 222 & 70 & 63 \\
\hline 11 & 1.52 & 6 & 0.28 & 6.8 & 55 & 78 & 7.17 & 3.5 & 235 & 50 & 135 \\
\hline 12 & 1.54 & 6 & 0.30 & 6.9 & 62 & 65 & 7.17 & 3.3 & 236 & 60 & 101 \\
\hline
\end{tabular}

CPAP levels were adjusted by the depth of immersion of the bubbler in the water column and were defined as MAP monitored proximal to the nasal interface. $\mathrm{HR}$, heart rate; $\mathrm{BP}$, blood pressure.
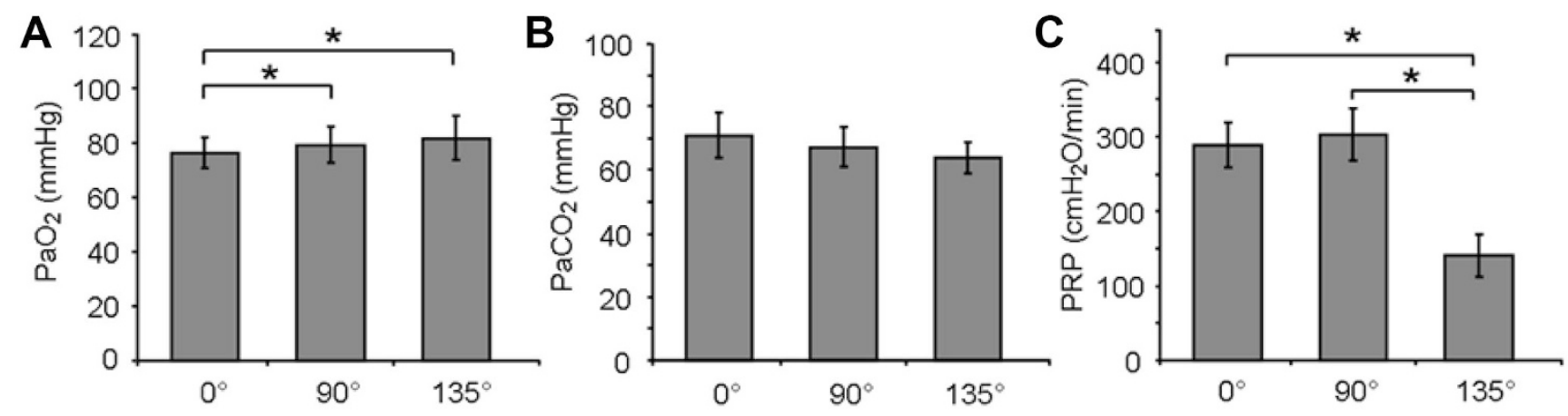

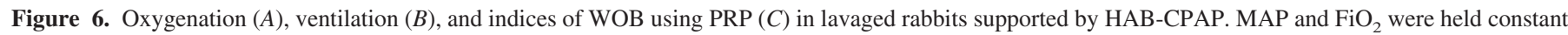
during the measurements of each animal. $p<0.05$. 
Table 2. Physiologic breathing parameters for lung-lavaged rabbits supported by $H A B-C P A P$

\begin{tabular}{clll}
\hline $\begin{array}{c}\text { Angle } \\
\text { (degrees) }\end{array}$ & $\begin{array}{c}\mathrm{RR} \\
\text { (breaths/min) }\end{array}$ & $\begin{array}{c}\Delta \mathrm{P}_{\text {es }} \\
\left(\mathrm{cm} \mathrm{H}_{2} \mathrm{O}\right)\end{array}$ & $\begin{array}{c}\mathrm{PRP} \\
\left(\mathrm{cm} \mathrm{H}_{2} \mathrm{O} / \mathrm{min}\right)\end{array}$ \\
\hline 0 & $88.1 \pm 9.8^{*} \ddagger$ & $3.7 \pm 0.5 \dagger$ & $289 \pm 30 \S$ \\
90 & $92.6 \pm 8.6 \ddagger$ & $3.5 \pm 0.5 \dagger$ & $303 \pm 35 \S$ \\
135 & $58.9 \pm 11.2^{*}$ & $2.4 \pm 0.6$ & $141 \pm 28$
\end{tabular}

$\S$ Data are means \pm SEM. Values not sharing the same superscript symbol differ, $p<0.05$.

abdominal distension, while being supported with any of the HAB-CPAP configurations.

\section{DISCUSSION}

The level of noninvasive respiratory support provided to spontaneously breathing lung lavaged juvenile rabbits during HAB-CPAP135 (Fig. 6) suggest that HAB-CPAP may be able to extend the range of premature infants who can be managed successfully with B-CPAP. In addition, the effects of bubbler angles between 0 and $180^{\circ}$ on $\Delta \mathrm{P}_{\mathrm{aw}}$ and $\Delta \mathrm{V}$ observed in model in vitro studies (Figs. 1-3) suggest a useful mode of HAB-CPAP adjustment to match the changing or specific needs of patients as their diseases progress or resolve.

The $\Delta \mathrm{V}$ measured in the static lung model with conventional B-CPAP (HAB-CPAP0) offers an explanation for the observations of Versmold et al. (10), who reported markedly slower $\mathrm{PaCO}_{2}$ increases in the chemically paralyzed animals supported by B-CPAP than with ventilator CPAP. Further, these measurable effects of B-CPAP on $\ddot{\mathrm{AV}}$ are consistent with the findings of Lee et al. (11) that B-CPAP in infants resulted in lower ventilation requirements, with similar blood gases, than were required with ventilator CPAP.

Attempts to augment the level of respiratory support provided with B-CPAP have included increasing bias flow that increases the magnitude and bandwidth of $\Delta \mathrm{P}_{\mathrm{aw}}$ delivered to a test lung via nasal prongs (12). Greater $\Delta \mathrm{P}_{\mathrm{aw}}$ should provide greater alveolar recruitment, gas exchange, and reduce WOB. The modest differences in $\Delta \mathrm{V}$ to a lung model resulting from increased bias flows observed with HAB-CPAP0, during our studies in vitro, are consistent with the findings of Pillow et al. (4) and Morley et al. (12), who observed no physiologic benefits using higher bias flow settings in spontaneously breathing subjects supported by B-CPAP.

Nekvasil et al. (13) attempted to augment the level of $\Delta \mathrm{P}_{\mathrm{aw}}$ using a B-CPAP system consisting of a funnel with the stem positioned at $90^{\circ}$ as the underwater seal. They applied this device in three intubated neonates and found that short-term gas exchange was similar to high-frequency ventilation when applied to the same neonates. None of the infants became apneic when using this B-CPAP system, whereas instances of apnea or severe bradypnea were observed during highfrequency ventilation. During the in vitro studies, Nekvasil et al. (13) also used ethanol and glycerin in the bubbler and noted that the frequencies of oscillation in $\mathrm{P}_{\mathrm{aw}}$ were inversely related to densities of the liquid. The physical properties of the bath liquid clearly can influence system function parameters, but water-based liquids are favored by practical and potential hazard considerations.
The forces required to reverse the direction of flow of the water as it reenters the bubbler, after the release of a bubble, and then to accelerate the water into the horizontal portion of the bubbler (Fig. 5) can account for the high $\Delta \mathrm{P}_{\text {aw }}$ observed during HAB-CPAP135. Estimations of surface tension forces in the bubbler by LaPlace equation calculations suggest that such effects on $\Delta \mathrm{P}_{\mathrm{aw}}$ are minor. Low points in $\mathrm{P}_{\mathrm{aw}}$ were observed when the column of gas contiguous with the airway rose to highest point in or just beyond the end of the bubbler. The breakup of the air column in the bubbler was associated with higher frequency and lower amplitude $\Delta \mathrm{P}_{\text {aw }}$ than those were observed during formation and expansion of the bubble contiguous with the airway. Kulkarni and Joshi (14) reported similar rapid depressurization immediately preceding detachment of bubbles from a submerged orifice. Many of these relatively small $\Delta \mathrm{P}_{\mathrm{aw}}$ are included in our algorithm used to calculate overall $\Delta \mathrm{P}_{\mathrm{aw}}$, resulting in a lower, more conservative, estimates of the mean values of $\Delta \mathrm{P}_{\mathrm{aw}}$.

The lower frequencies of $\Delta \mathrm{P}_{\mathrm{aw}}$ during HAB-CPAP135 allow more time for volume delivery to the lung model than is observed with HAB-CPAP0 and during most applications of high-frequency oscillatory ventilation (HFOV) in preterm infants. It is interesting to note that tidal volumes of 2 to $3 \mathrm{~mL}$, delivered to our lung model through leaky nasal prongs during nasal HAB-CPAP135, approximated the volumes measured in infants intubated endotracheally and receiving HFOV (15). We do not know the differences in lung mechanics between the mechanical test lung and the premature infants on HFOV. However, the resistance to gas flow in binasal short prongs is a fraction of the resistance of endotracheal tubes used in preterm infants (16), which very likely contributes to the similarities in delivered tidal volumes. These tidal volumes, although small, may contribute to gas exchange through direct bulk alveolar ventilation. The high-frequency oscillations observed during HAB-CPAP135 may also retain the benefits of HFOV that have been attributed to enhanced gas diffusion and lung recruitment with tidal volumes at or below the anatomic dead space (17).

Conventional high-frequency ventilators are capable of delivering very high $\Delta \mathrm{P}_{\mathrm{aw}}$ but operate at a single frequency, whereas HAB-CPAP135 provides lower dominant frequencies at broad bandwidths of associated intensities. Diseased lungs are remarkably heterogeneous (18), and the spectra of pressure frequencies produced by HAB-CPAP135 may be more effective than the high-frequency ventilators to complement the array of airspaces that need ventilatory support.

Improvements in $\mathrm{PaO}_{2}$ in the animals during $\mathrm{HAB}$ CPAP135 may reflect alveolar recruitment from $\mathrm{P}_{\mathrm{aw}}$ oscillations at broadband frequencies superimposed on the spontaneous breathing efforts. Biologically variable ventilation applies variations in tidal volume and respiratory frequency settings similar to normal variations in the human breathing pattern. In lung-injured animals, biologically variable ventilation has been shown to improve gas exchange, lung mechanics (19), and endogenous surfactant production (20) better than conventional volume-cycled ventilation. Suki and coworkers (21-23) attributed these physiologic effects to stochastic resonance, which describes the complex relationship of lung stability 
when biologic noise is added to the nonlinear respiratory system. Pillow and Travadi (3) linked the concept of noise, created by B-CPAP superimposed on mean CPAP and spontaneous respiratory efforts to stochastic resonance and enhanced lung function.

The PRP values obtained during HAB-CPAP135 were $\sim 50 \%$ lower than values during HAB-CPAP0 and HABCPAP90. This difference suggests valuable clinical utility for HAB-CPAP135 in premature infants for whom WOB can represent a substantial challenge. The combination of lower PRP and higher $\mathrm{PaO}_{2}$ at the same MAP with comparable $\mathrm{PaCO}_{2}$ during HAB-CPAP135 implies improved lung mechanics and decreased intrapulmonary shunting, possibly because of the recruitment of collapsed respiratory units. However, lung mechanics and functional residual capacities were not measured in the animals because of the inherent limitations of the leaky nasal prongs interface.

The two animals that became apneic were not distinguishable from the others by the levels of respiratory compromise (Table 1). Significant reductions in the spontaneous minute ventilation (24) and apnea (25) have been observed in subjects with normal $\mathrm{PaCO}_{2}$ receiving high-frequency ventilation. The efficiency of ventilation provided by HAB-CPAP135 and its ability to off-load inspiratory WOB and eliminate $\mathrm{CO}_{2}$ may explain the reduction in ventilatory drive within these animals. However, the observed apnea in these normocapnic animals may also be related to inhibition, by high-frequency pressure oscillations, of afferent mechanoreceptors in the lung and the chest wall. This phenomenon has also been observed previously in spontaneously breathing subjects during highfrequency ventilation (25).

The relevance of this study to human therapy is limited by the use of an animal model with nasal anatomies different from those of prematurely born human infants. Our animals also had mature lung structure and surfactant metabolism. The latter limits the ability of lavage to provide a stable surfactantdeficient model, which in turn limits the study of the long-term effects of the different modes of respiratory support. Further, frequency responses of the respiratory system to noise in $\mathrm{P}_{\mathrm{aw}}$ in lavaged animal lungs are likely to be different from those of preterm infants. Although leak around nasal prongs in the in vitro studies were well controlled, leaks during the rabbit studies could have changed within the study groups and were likely different from animal to animal. Finally, and most importantly, the long-term safety and efficacy of applying HAB-CPAP135 to children has not been established.

Despite these limitations, the results from these studies with experimental animals suggest that HAB-CPAP135 may be capable of increasing the fraction of newborns in whom respiratory support can be managed noninvasively. If this study in experimental animals can be translated into clinical practice more children could avoid the risks associated with intubation and invasive modes of ventilation. Future studies in human infants need to be conducted to test this hypothesis.

\section{REFERENCES}

1. Jobe AH, Kramer BW, Moss TJ, Newnham JP, Ikegami M 2002 Decreased indicators of lung injury with continuous positive expiratory pressure in preterm lambs. Pediatr Res 52:387-392

2. Aly H, Milner JD, Patel K, El-Mohandes AA 2004 Does the experience with the use of nasal continuous positive airway pressure improve over time in extremely low birth weight infants? Pediatrics 114:697-702

3. Pillow JJ, Travadi JN 2005 Bubble CPAP: is the noise important? An in vitro study Pediatr Res 57:826-830

4. Pillow JJ, Hillman N, Moss TJ, Polglase G, Bold G, Beaumont C, Ikegami M, Jobe AH 2007 Bubble continuous positive airway pressure enhances lung volume and gas exchange in preterm lambs. Am J Respir Crit Care Med 176:63-69

5. Ammari A, Suri M, Milisavljevic V, Sahni R, Bateman D, Sanocka U, RuzalShapiro C, Wung JT, Polin RA 2005 Variables associated with the early failure of nasal CPAP in very low birth weight infants. J Pediatr 147:341-347

6. Aly H 2009 Ventilation without tracheal intubation. Pediatrics 124:786-789

7. Baydur A, Behrakis PK, Zin WA, Jaeger M, Milic-Emili J 1982 A simple method for assessing the validity of the esophageal balloon technique. Am Rev Respir Dis 126:788-791

8. Willis BC, Graham AS, Yoon E, Wetzel RC, Newth CJ 2005 Pressure-rate products and phase angles in children on minimal support ventilation and after extubation. Intensive Care Med 31:1700-1705

9. Gupta S, Sinha SK, Tin W, Donn SM 2009 A randomized controlled trial of post-extubation bubble continuous positive airway pressure versus Infant Flow Driver continuous positive airway pressure in preterm infants with respiratory distress syndrome. J Pediatr 154:645-650

10. Versmold HT, Brunstler I, Schlosser C 1982 High Frequency Oscillation durch Blubber-CPAP beschleunigt $\mathrm{CO}_{2}$ Elimination. Thieme, Stuttgart, Germany, pp $159-162$

11. Lee KS, Dunn MS, Fenwick M, Shennan AT 1998 A comparison of underwater bubble continuous positive airway pressure with ventilator-derived continuous positive airway pressure in premature neonates ready for extubation. Biol Neonate 73:69-75

12. Morley CJ, Lau R, De Paoli A, Davis PG 2005 Nasal continuous positive airway pressure: does bubbling improve gas exchange? Arch Dis Child Fetal Neonatal Ed 90:F343-F344

13. Nekvasil R, Krátký J, Penková Z, Stejskal J 1992 High frequency "bubble" oscillation ventilation in the neonatal period [in Czech]. Cesk Pediatr 47:612-614

14. Kulkarni AA, Joshi JB 2005 Bubble formation and bubble rise velocity in gas-liquid systems: a review. Ind Eng Chem Res 44:5873-5931

15. Sturtz WJ, Touch SM, Locke RG, Greenspan JS, Shaffer TH 2008 Assessment of neonatal ventilation during high-frequency oscillatory ventilation. Pediatr Crit Care Med 9:101-104

16. De Paoli AG, Morley CJ, Davis PG, Lau R, Hingeley E 2002 In vitro comparison of nasal continuous positive airway pressure devices for neonates. Arch Dis Child Fetal Neonatal Ed 87:F42-F45

17. Butler WJ, Bohn DJ, Bryan AC, Froese AB 1980 Ventilation by high-frequency oscillation in humans. Anesth Analg 59:577-584

18. Randell SH, Mercer RR, Young SL 1990 Neonatal hyperoxia alters the pulmonary alveolar and capillary structure of 40-day-old rats. Am J Pathol 136:1259-1266

19. Arold SP, Mora R, Lutchen KR, Ingenito EP, Suki B 2002 Variable tidal volume ventilation improves lung mechanics and gas exchange in a rodent model of acute lung injury. Am J Respir Crit Care Med 165:366-371

20. Arold SP, Suki B, Alencar AM, Lutchen KR, Ingenito EP 2003 Variable ventilation induces endogenous surfactant release in normal guinea pigs. Am J Physiol Lung Cell Mol Physiol 285:L370-L375

21. Alencar AM, Arold SP, Buldyrev SV, Majumdar A, Stamenovic D, Stanley HE, Suki B 2002 Physiology: dynamic instabilities in the inflating lung. Nature 417:809811

22. Suki B, Alencar AM, Sujeer MK, Lutchen KR, Collins JJ, Andrade JS Jr, Ingenito EP, Zapperi S, Stanley HE 1998 Life-support system benefits from noise. Nature 393:127-128

23. Wiesenfeld K, Moss F 1995 Stochastic resonance and the benefits of noise: from ice ages to crayfish and SQUIDs. Nature 373:33-36

24. Calverley PM, Chang HK, Vartian V, Zidulka A 1986 High-frequency chest wall oscillation. Assistance to ventilation in spontaneously breathing subjects. Chest 89:218-223

25. England SJ, Onayemi A, Bryan AC 1984 Neuromuscular blockade enhances phrenic nerve activity during high-frequency ventilation. J Appl Physiol 56:31-34 